\title{
Use of SIICC / ACR damage index in adolescents with SLE
}

\author{
Ludmila Bogmat, Nataly Shevchenko, Elena Matvienko \\ From 21st European Pediatric Rheumatology (PReS) Congress \\ Belgrade, Serbia. 17-21 September 2014
}

\section{Introduction}

System Lupus Erythematobus (SLE) is one of the most severe and unfavorable to its course of rheumatic diseases. Poor prognosis of SLE development has irreversible changes of internal organs. The number and type of there have accounted for by SIICC/ACR Damage Index in adults. However, such changes have found in children also.

\section{Objectives}

In order to timely diagnosis of irreversible changes of internal organs in systemic lupus erythematosus (SLE) 44 adolescents with SLE medical history have analyzed.

\section{Methods}

The age of patients at the time of the study were 12,67 \pm 3,17 years. SLE debut age equaled $12,65 \pm 2,87$ years. Duration of illness was $39,36 \pm 4,17$ months.

The diagnosis of SLE exhibited respectively ACR classification criteria (1997). SIICC /ACR Damage Index was assessed in all patients. Comparison of estimates of the index had conducted at duration of illness before and more than three years.

\section{Results}

SLE manifested the following clinical syndromes: articular $(84.3 \%)$, skin $(82.3 \%)$, renal $(55.4 \%)$, cardial $(59.8 \%)$, pulmonary (35.7\%), cerebral (31, 2\%), Blood disorders (64.3\%), antiphospholipid syndrome (11.9\%).

Most patients had subacute start option (61.4\%) and moderate activity of SLE (45.41\%).

All adolescents were treated with glucocorticoids; the mean total dose was $11326 \pm 2435 \mathrm{mg}$ per patient. Combination therapy with glucocorticoids and cytotoxic drugs was at $70.3 \%$ of patients. Ultrahigh doses of methylprednisolone ("pulse"- therapy) have conducted in $37.5 \%$ of patients.

The authors have found that $90.9 \%$ of adolescents with SLE have the damage that includes the scale SIICC /ACR Damage Index for adult patients. Average score SIICC / ACR Damage Index in adolescents with SLE was $2,72 \pm 0,84$ points. Frequency of cumulative damage and the total score SIICC/ACR Damage Index increased with disease duration of more than three years. The structure damage had the greatest increase of cardiovascular changes $(21.2 \%$ vs. $12.2 \%)$, neuropsychiatric disorders $(12.1 \%$ vs. $3.0 \%)$, renal disease $(3.0 \%$ vs $0.9 \%)$. Aseptic necrosis of bone tissue occurred when the duration of the disease for more than three years only (3.1\%).

\section{Conclusion}

Research proves that children with SLE should be have evaluated to assess the scale of damage. Adaptation of these scales have needed for children and adolescents.

\section{Disclosure of interest}

None declared.

Published: 17 September 2014

doi:10.1186/1546-0096-12-S1-P329

Cite this article as: Bogmat et al:: Use of SIICC / ACR damage index in

adolescents with SLE. Pediatric Rheumatology 2014 12(Suppl 1):P329. 